\title{
Consumo de objetos eróticos por mulheres: processos e contextos em mudança
}

\section{Consumption of erotic objects by women: changing processes and contexts}

\section{El consumo de objetos eróticos por mujeres: el cambio en los procesos y contextos}

\author{
iD Anelise Montañes Alcântara \\ Universidade Federal do Paraná, Curitiba, Paraná, Brasil. \\ liumontanes@gmail.com \\ iD Marlene Tamanini \\ Universidade Federal do Paraná, Curitiba, Paraná, Brasil. \\ tamaniniufpr@gmail.com
}

Resumo: Este texto analisa o conteúdo das relações envolvidas com o consumo e o uso de objetos eróticos por mulheres, no contexto dos mercados eróticos e de suas práticas de venda. Esse conteúdo é uma forma de engajamento com suas subjetividades e intimidade, resguardadas as particularidades na construção de si, relativas à vivência e à diversidade da sexualidade. O artigo emerge de indagações a possíveis decolonizações na construção e na experiência de mulheres relativas à sexualidade e ao modo como elas interagem com os objetos. Ao contrário de um passado repressivo e voltado à família è̀ reprodução, na contemporaneidade, a sexualidade envolve discursos de mercado, direito ao prazer e à agência de si, de tal modo que há produção de conhecimento das 
ressignificações e dos processos de decolonização no campo da sexualidade. A análise aqui apresentada se baseou em observações participantes em sex shops e em boutiques sensuais, diário de campo e em entrevistas com 10 mulheres de Curitiba-PR.

Palavras-chave: Mercados eróticos. Objetos eróticos. Sexualidades. Gênero. Consumo.

Abstract: The attempt in this paper is to analyze the content of the relations involved with the consumption and use of erotic objects by women, in the context of the erotic market and its selling practices. This content is a form of engagement that holds its subjectivity and intimacy, preserving its particularities in the construction of itself referring the living experiences and their sexual diversities. The paper gathers its data from inquiring the possible decolonization in the construction and in women experience, from their sexualities and from the way in which they interact with the objects. Unlike the repressive past focused on family and on reproduction, in our times sexuality involves the market discourse, the right to pleasure and an agency of oneself, in a way that there is a knowledge production of new significations and of decolonization processes in the field of sexuality. The analysis is grounded on participant observations in sex shops and in sensual boutiques, field journals and interviews with 10 women from Curitiba, Paraná.

Keywords: Erotic markets. Erotic objects. Sexualities. Gender. Consumption.

Resumen: El intento en este artículo es analizar el contenido de las relaciones involucradas con el consumo y el uso de objetos eróticos por parte de las mujeres en el contexto de los mercados eróticos y de sus prácticas de venta. Dicho contenido es una forma de compromiso que mantiene su subjetividad y privacidad íntima, 
preservando sus particularidades en la construcción de sí mismas en relación con la experiencia y la diversidad de su sexualidad. El artículo surge de preguntas sobre posibles descolonizaciones en la construcción y experiencia de las mujeres relativas a su sexualidad y a la forma en que interactúan con los objetos. De manera contraria, desde un pasado represivo y centrado en la familia, preferentemente en la reproducción, en nuestros tiempos la sexualidad implica el discurso de mercado, el derecho al placer y una agencia de uno mismo, de manera que haya una producción de conocimiento de nuevas significaciones y procesos de descolonización en el campo de la sexualidad femenina. Este análisis se basa en observaciones de participantes en sex shops y en boutiques sensuales, diarios de campo y entrevistas con 10 (diez) mujeres de la ciudad de Curitiba, Paraná.

Palabras clave: Mercado erótico. Objetos eróticos. Sexualidades. Gênero. Consumo.

Data de recebimento do artigo: 19/04/2018

Data de aprovação do artigo: 18/09/2019 


\section{Introdução}

Em um passado não muito distante, a sexualidade estava a serviço da reprodução. A intimidade era assunto pouco discutido naquilo que se caracterizava como a moral das alianças de casamento, cuja finalidade procriativa era regra. Esta servia como apoio jurídico para o reconhecimento de patrimônio, herança de filhos e a ordem do dever conjugal para colonização do prazer sexual, considerado desnecessário à reprodução. Embora esse discurso tenha se atualizado com muita força em contextos políticos contemporâneos, este artigo se concentra nas dinâmicas que indicam diferentes vivências da subjetividade e da intimidade de mulheres. Algumas vezes essas dinâmicas podem parecer híbridas de argumentos, enunciados e de práticas, baseadas em conteúdo que reforçam lugares de alteridade sexistas e, portanto, colonizadas pela busca do prazer voltado só para o masculino.

Analisar como se constrói o consumo de objetos eróticos por mulheres que se engajam com os discursos deste mercado e os sentidos possíveis de decolonialidade a partir dele é caracterizar o uso do termo como o reconhecimento dos lugares de enunciação das mulheres, bem como reconhecer a existência de sua intimidade e de seu desejo sexual, o que, para o contexto geral de suas trajetórias, são lugares diversos, variados e, portanto, marcados por diferenças culturais, linguísticas e materiais. Para o texto, ressaltam-se os sentidos de uma descolonização da sexualidade, condicionada por modelos culturais patriarcais, vinculada a papéis e funções sexuais, pressupostos de estar a serviço de uma masculinidade desejante, na condição de passividade em relação à existência do desejo e de uma narrativa feminina. 
Consumo de objetos eróticos por mulheres: processos e contextos... Anelise Montañes Alcântara • Marlene Tamanini

É preciso ressaltar as narrativas que emergem do uso dos produtos eróticos, uma vez que elas não são homogêneas ou dizem respeito a um modelo único de vivência da sexualidade. Essa tensão nos coloca a necessidade de superar o risco da homogeneização da experiência das mulheres (tanto com os produtos eróticos, quanto com sua sexualidade) e amplia a atenção às questões da diferença nas experiências. Neste caso, diferentemente das questões raciais, étnicas e culturais, tratadas por autoras como Rita Felski (2003), bell hooks (1995), Patricia Hill Collins (2000) ou Stuart Hall (2003), aquelas dizem respeito, particularmente, à subjetividade, à intimidade e ao modo como se constitui a narrativa.

Como ensina Haraway (1991), trata-se, portanto, de um conhecimento situado e do desafio de dar voz a outras vozes. Assim, o que se apresenta é parte de um interesse cultural em compreender os sentidos da decolonialidade, como um esforço de afastar as essencializações a respeito da feminilidade e da sexualidade. A decolonidade aqui é também da parte das pesquisadoras em assumir um lugar preocupado com o desprendimento subjetivo, epistêmico, econômico e político relativo ao projeto de dominação ocidental no que tange à economia dos corpos e da sexualidade. Desestabilizar a colonialidade do poder, do saber e do ser, conforme analisa María Lugones (2014).

As mulheres que fruem das materialidades dos objetos eróticos em suas práticas sexuais estão produzindo outros sentidos, não apenas relacionados à dominação masculina, mas configurando um alargamento das normas de sexualidade. Os objetos, seus usos e os modos como são consumidos estão postos no âmago de tensões teóricas, políticas e epistemológicas. Isso não permite que sejam tomados como estruturados apenas pelo mercado para atender ao desejo masculino, (afirmações não incomuns em cer- 
Consumo de objetos eróticos por mulheres: processos e contextos... Anelise Montañes Alcântara • Marlene Tamanini

tos espaços), porque atendem ao desejo de mulheres de se produzirem pelas suas ações. É necessário, portanto, observar a ampliação dos usos, dos consumos e dos sentidos dos consumos dos produtos eróticos, bem como as construções de prazer realizadas pelas consumidoras deles nas ressignificações e no imaginário sobre sua vida sexual, corpos, parceiros e prazer sem parceiros, ou seja, o que elas mesmas constroem para si.

Como afirma Felski (2003), corre-se o risco da homogeneização, se forem desconsideradas as experiências diversas das muIheres, que, em sua posicionalidade de sujeito, traduzem, interpretam e se apropriam dos objetos em suas relações; e o fazem conforme entendem ser o melhor. Por isso, em nossa linguagem, como autoras, consideramos que a posição das mulheres vai além de leituras teóricas que estão circunscritas à crítica ao mercado e/ ou às análises que indicam haver uma objetivação realizada sobre as mulheres nestes consumos por ele vir do mercado. As mulheres usuárias e vendedoras não são passivas, nem o fazem para se aproximar dos modelos masculinos, tampouco, só reiteram o mercado como dependentes. Sua relação não se coaduna com a subjugação.

O campo mostra que elas também fazem uso criativo dos objetos a favor de si, tanto no trabalho/venda desses itens em busca de autonomia econômica quanto no desejo de sexo ou na busca de relacionamentos prazerosos. Elas constroem sentidos próprios no que tange às relações com o direito ao prazer, à sua sexualidade e às possibilidades de escolha, liberdade e agência em relação à sua subjetividade e intimidade. A extração do prazer do consumo, conforme constatamos, vai além do discurso que elas também acionam e que, por vezes, se circunscreve na manutenção do casamento ou na necessidade de apimentar uma relação desgastada. 
Consumo de objetos eróticos por mulheres: processos e contextos... Anelise Montañes Alcântara • Marlene Tamanini

Esses aspectos, contudo, também são carregados de autonomia e de criatividade, de si e para si, para manter relações que elas escolhem manter. Isso ficou claramente demarcado no material analisado da tese defendida em novembro de 20171, embora o campo da tese tenha sido realizado a partir de fontes e perspectivas teóricas diferentes das que estamos discutindo neste texto e ele não faz parte deste artigo. Contudo, ele serve para matizar o tema com as observações de campo multissituadas e com temporalidades diferentes na interface com o mercado, com suas práticas e os modos de consumo das usuárias e vendedoras. Serve também para lembrar que mais recentemente, a entrada dos consumidores homens não é irrelevante.

Neste artigo, analisam-se os conteúdos de uma reflexividade contraditória que é exercida com o consumo de objetos eróticos. Isso requer observá-los como parte de uma tecnologia de agenciamentos e de agências de si que são tensas e que tem posições de institucionalização de práticas para os cuidados de si e o governo de si, bem como do outro. É com processos complexos de mudanças de concepções relativas à sexualidade, não mais passível de enquadramento nos moldes do amor romântico do passado (GIDDENS, 1991, 1993) marcado por dependências e voltado, prioritariamente, à reprodução (portanto, colonializado) que, contemporaneamente, se erotizam sexo, sexualidade e relações com a intimidade.

Essas relações se decolonizam com fantasias, dinâmicas e estratégias de compra, venda e uso de produtos eróticos com parceiros ou nas experiências sexuais individuais. Esses processos também se inserem em subjetivações que acolhem, escolhem

\footnotetext{
1 A tese se utiliza da teoria ator-rede e das teóricas feministas para pensar como o orgasmo é constituído a partir de uma rede heterogênea que conectam humanos e não humanos. Nessas relações visualiza-se a existência da materialidade em vários objetos eróticos que ajudam e ao mesmo tempo fazem parte da performatização de corpos e de orgasmos em práticas sexuais das mulheres que estiveram ou estavam em relacionamentos com homens. (ALCÂNTARA, 2017).
} 
Consumo de objetos eróticos por mulheres: processos e contextos... Anelise Montañes Alcântara • Marlene Tamanini

e desejam novas experiências compatíveis com os desejos das mulheres e com a institucionalização de um mercado em expansão, bem como com os processos de individuação dos sujeitos na sociedade contemporânea. Trata-se, em tudo isso, da produção e da venda de produtos com seus saberes (FOUCAULT, 1995) já incorporados como eróticos e que são encontrados nas lojas de sex shops, boutiques sensuais, catálogos, motéis, salões de beleza ou são apresentados em ambientes virtuais como instrumentos que operam a promessa de felicidade individual e como parte do próprio sucesso e autorrealização feminina. Esses produtos têm tecnologia, narrativas e estratégias de venda incorporadas com destaques em semióticas que acionam a promessa de satisfação sexual e a necessidade da busca do prazer emocional. Esse saber sobre o que eles são, como são e o que podem fazer é altamente compartilhado por vendedoras e consumidoras e, pedagogicamente, ensinado pelas vendedoras às usuárias.

Para o nosso estudo, todas as participantes possuíam vida sexual ativa, consumiam produtos eróticos em suas práticas afetivas e sexuais, eram maiores de 24 anos, somente uma era negra, no mínimo possuíam grau de escolaridade de ensino médio. Somente duas exerciam suas práticas sexuais com parceiros homens de maneira mais descompromissada; as outras em relacionamentos estáveis, institucionalizados e monogâmicos. Elas compram ou vendem os produtos, engajam-se com seu uso na expectativa de obter prazer sexual e emocional. Suas performances de gênero, de sexo e de desejo estão conectadas aos objetos e, ao mesmo tempo, aos múltiplos imaginários sobre como podem se relacionar com parceiros homens, com o marido, namorado ou de forma descompromissada. Esse lugar da voz, da experiência e da narrativa descoloniza diversos aspectos dos seus corpos e da circunscrição da sexualidade como assunto do silêncio e do privado. 


\section{O consumo, a fruição e os objetos eróticos}

A qualificação de nossa discussão a respeito de consumo é uma conversa que vai para além da simples relação de uma pessoa com um objeto. Trata-se da busca pelo prazer físico e emocional nas compras e usos de objetos eróticos (no caso das consumidoras) e da apropriação e adensamento de saberes a respeito de usos e das vendas (no caso das vendedoras, que nesta função de vender podem ser elas próprias também consumidoras). Tal disposição não foi aguçada somente pelos benefícios funcionais ligados aos atributos técnicos dos objetos, mas se conecta especialmente com a vontade das consumidoras de experimentar uma "emoção" por meio da compra e da relação com o objeto.

Conforme analisa Bragaglia (2010), essa emoção diz respeito a um sentimento intenso de prazer ligado ao desejo (querer intenso) pelo objeto que gera tal emoção. Nesse aspecto, a experiência se ressalta pela fantasia e criatividade do uso, tanto quanto alude a um bem-estar via sensorial, a partir de nossos sentidos - o corpo, o físico - e por meio da nossa imaginação. Nesse sentido, "há muito tempo os consumidores deixaram de simplesmente buscar nos produtos os benefícios relacionados aos atributos técnicos, à funcionalidade" (BRAGAGLIA, 2010, p. 111). Na mesma linha, Campbell (2006) aponta com seu conceito de hedonismo, quando argumenta que o prazer emocional e esse consumo da parte das mulheres estariam possibilitando o exercício do autoconhecimento por meio da reflexão sobre seus gostos.

O autor demonstra a identidade pelo gosto e pelo uso do consumo por meio do seu conceito de craft consumer, isto é, consumidor artesão. Esse tipo de consumidor seria um guia para compreensão da prática do consumo na sociedade contemporânea, 
Consumo de objetos eróticos por mulheres: processos e contextos...

Anelise Montañes Alcântara • Marlene Tamanini

rejeitando qualquer sugestão de que o consumidor seja um fantoche indefeso de forças exteriores. A hipótese é que indivíduos consomem principalmente pelo desejo de tomar parte em atos criativos de expressão de sua individualidade. Esse elemento, a nosso ver, retira o aspecto do poder coercitivo, levando a um sentido de si, que, marcuseanamente falando, está na esfera do lúdico, como um lugar libertador.

O consumidor artesanal, na concepção de Campbell, investe em sua personalidade ou individualidade e no objeto produzido. A expressão "consumo artesanal" é usada similarmente para fazer referência a atividades em que indivíduos ao mesmo tempo concebem e fazem os produtos que eles próprios consomem. Mas, também, a "criatividade para juntar" ou atos de fazer combinações que demonstrem o gosto pessoal. Por exemplo, aplicar rendas em camisetas compradas prontas, a fim de exprimir individualidade, singularidade e expressar criatividade.

As participantes da pesquisa revelaram gostos e preferências ao prepararem um verdadeiro cenário com o uso de vários objetos: velas aromáticas, óleos para massagens, uso de pétalas de rosa artificiais, lingeries provocantes, músicas e comidas que faziam combinações em arranjos com as fantasias utilizadas. Assim como a capa peniana ${ }^{2}$, ou anéis penianos ${ }^{3}$ em dedos, vibradores, dildos ou pênis realísticos, e o uso de dois vibradores simultaneamente, um no clitóris enquanto outro estimula o canal vaginal. Isso revela a criatividade, a recreação e a imaginação com o uso da materialidade desses objetos.

\footnotetext{
2 A palavra que faz referência ao órgão humano pênis tem sido retirada ou substituída quando associada com a capa ou aos anéis. Novos nomes têm sido performados. (ALCÂNTARA, 2017).

3 Percebemos por meio da materialidade do anel e de sua denominação mais recente "anel vibratório" as transformações contemporâneas da sexualidade feminina na medida em que as mulheres podem interagir com o anel de outras formas, o que por sua vez deslocam do centro, mesmo que de forma discreta, o pênis humano como produtor de orgasmos femininos nessa abordagem material e social. (ALCÂNTARA, 2017).
} 
Para Campbell (2006), a expressão da individualidade e autenticidade pessoais no consumo estaria em contraposição ao caráter homogeneizador da mercantilização, no intuito de tornar as coisas especiais. De forma coerente com esse raciocínio, as muIheres consumidoras usam a grande oferta de produtos e novidades para recriar (constantemente) a si mesmas, expressando sentimentos intermediados pelos objetos, dando a eles os usos que entendem ser mais interessantes, mais criativos e mais livres, como uma agência que cria lugares de narrativa e até novas materialidades para os objetos.

A junção de ideias e as mudanças nos contextos de inserção também produziram a história particular da sex shop. Desenvolvida por uma mulher, Beate Uhse, no início dos anos 60, na Alemanha, era destinada a mulheres e compunha conteúdo de uma perspectiva voltada para a saúde sexual feminina. No entanto, as sex shops se configuraram de outra maneira quando chegaram ao mercado dos Estados Unidos, ressignificando esses espaços como masculinizados, mais associados à transgressão e à pornografia, nos quais é possível encontrar cabines com filmes pornôs para masturbação masculina.

Na última década, esse mercado vem sendo transformado e deslocado dos conhecidos sex shops "masculinizados" para diversos locais que feminizam esses contextos, como lojas de lingerie, boutiques sensuais e vendas por catálogos. Desse modo, assiste-se a uma mudança nos espaços de venda de produtos eróticos, que carregam a lógica de um erotismo politicamente correto, afastando a ideia do sujo, da patologia e dos perigos, como bem pontua a antropóloga Maria Filomena Gregori (2012), com sua etnografia realizada em sex shops de São Paulo. Gregori (2005) encontra uma espécie de culto do saudável, com a junção do discurso de cuidado 
Consumo de objetos eróticos por mulheres: processos e contextos... Anelise Montañes Alcântara • Marlene Tamanini

com o corpo e com referências à diversão produzida nesse campo erótico, esvaziando-o de sentidos que possam colocá-lo como fonte de mal-estar.

Entendemos que nesta construção se juntam à materialidade das lojas e dos objetos eróticos os novos sentidos que são produzidos para legitimar variadas práticas sexuais, como o sadomasoquismo, por exemplo, encontrado no livro e com posterior filmagem dos "50 tons de cinza". Distante do patológico e do sujo, esses novos sentidos tornam as relações assépticas, clean e até românticas. Conforme analisa Luciana Castello da Costa Leme Walther (2017), muitos objetos têm uma conotação infantilizada, como bichos de pelúcia que servem para escamotear os vibradores e objetos nas cores rosa e lilás, lembrando brinquedos infantis das meninas. Esses cenários joviais e jocosos conferem aspectos de neutralidade aos lugares de venda e aos objetos, passando uma ideia de inofensividade, que pode orientar comportamentos em direção a posturas descontraídas, brincalhonas e mais palatáveis às consumidoras femininas. Embora seja uma estratégia de venda, esses espaços são menos colonizados pelo desejo masculino quando apropriados pelas mulheres.

Outro aspecto interessante é a profusão de formas fálicas que se harmoniza com toda a materialidade circundante, suscitando posturas triviais e tranquilas, segundo Walther (2017). Constrói-se com aquelas junções ambientes convidativos às consumidoras, como lojas bonitas e agradáveis em shoppings, com embalagens de bom gosto, design sofisticado e sem nada que indique em sua fachada que se trata de um espaço de venda de produtos voltados para o prazer sexual.

Lorena Mochel Reis (2017), assim como Gregori (2012, 2005) e Alcântara (2013, 2017), analisa quanto desse mercado está di- 
Consumo de objetos eróticos por mulheres: processos e contextos... Anelise Montañes Alcântara • Marlene Tamanini

recionado às mulheres que não são tão jovens e que em geral se identificam como heterossexuais, seja como vendedoras, consultoras ${ }^{4}$, consumidoras, empresárias e, porque não dizer, também pesquisadoras envolvidas com essa temática. As autoras mostram como esse campo vem se construindo e se legitimando, uma vez que nele há uma incitação para a venda, a fruição, o consumo desses produtos para excitação, ereção, gozo, ejaculação, em uma expectativa que corresponde à própria materialização desses produtos como junção de diversos elementos. Contemporaneamente, há também um aumento da variedade de produtos considerados eróticos. Esses produtos são assimilados às novas maneiras de desejo e de se viver a sexualidade: objetos em formato de língua humana para a prática do sexo oral, vibradores rotativos, vibradores para os bicos dos seios e saco escrotal, vibradores que sugam (a vácuo) o clitóris e até preservativos com medicamentos para retardar a ejaculação.

Todos esses processos descolonizam a sexualidade e o gênero de sua circunscrição ao silêncio, à moralidade do privado, à impossibilidade para mulheres, à passividade sexual feminina e de sua demarcação como prostituição ou pornografia, ainda que se pudessem suscitar importante fonte para as teorias da colonização do desejo. Trata-se de uma maneira de instituir e interiorizar práticas eróticas na vida das consumidoras, sem negar a valorização da individualidade, da personalidade feminina, espaço para a agência das mulheres, que as levam a se afirmar como sujeitos perante o corpo, o sexo e a sexualidade a partir dos cuidados de si e da reflexividade. Podemos então pensar os mercados eróticos e os objetos eróticos como reforçadores dos cuidados de si, a partir da noção de sexo associado à saúde, da busca e satisfação

4 Vendem objetos eróticos por meio dos catálogos de produtos. 
Consumo de objetos eróticos por mulheres: processos e contextos... Anelise Montañes Alcântara • Marlene Tamanini

dos prazeres corporais, da preocupação com a higiene corporal e do embelezamento do corpo, sobretudo quando pensamos em produtos como cosméticos e lingeries. Nesse caminho, os modos de existência feminina são múltiplos e estão em franca mudança.

As universalizações dos termos mulher ou mulheres mascaram realidades heterogêneas. $O$ "sujeito das mulheres não é mais compreendido em termos estáveis e permanentes". (BUTLER, 2003, p. 18). No século XXI, as mulheres estão preocupadas com o próprio corpo, erotismo, beleza, maternidade, entre outros temas, procurando ordenar vida afetiva, sexual, profissional, familiar e cuidado de si. (RAGO, 2006). Como bem coloca Rago (2006), cuidar de si pode ser uma maneira de facilitar a relação com o outro, pois conhecemos melhor nosso corpo, damos maior atenção à saúde e cuidamos melhor de nós mesmos.

Os aspectos que se referem aos cuidados de si dialogam com as transformações no modo de socialização e de individualização das mulheres, criando uma nova economia dos poderes femininos diferentes de lugares atribuídos aos homens e às mulheres de forma muito rígida e restrita como ocorria nas sociedades tradicionais. Hoje, essa dinâmica é mais flexível e maleável. As participantes desta pesquisa desejam cuidar do corpo e da sua beleza, permanecendo jovens e sedutoras durante mais tempo; os mercados de produtos eróticos procuram produzir mercadorias direcionadas a esses desejos com a produção de equipamentos que são usados por elas para os cuidados de si, ao mesmo tempo em que fomentam esses desejos. 


\section{Sentidos de decolonialidades: mulheres vendedoras}

Nesta pesquisa, foram entrevistadas: Joana ${ }^{5}$ (24 anos), Virgínia (32 anos), Frida (32 anos) e Sara (32 anos) como vendedoras de produtos eróticos e que também desempenhavam papéis de consumidoras. Todas são brancas. Frida e Sara realizavam trabalho em lojas de sex shops do centro de Curitiba-PR; as outras com vendas diretas ${ }^{6}$. Somente Frida estava namorando, Virgínia estava em uma união estável há três anos e as demais eram casadas, sendo Joana há 7 anos, Sara há 10 anos. Frida (32 anos) trabalhava há mais de 10 anos em uma sex shop que possuía cabines para masturbação. As outras vendedoras estavam a menos de cinco anos atuando nesse mercado. Todas relataram que antes de trabalhar com produtos eróticos tinham em seu imaginário a representação, também social, de que pessoas que vendiam e usavam esses produtos eram desviantes. Significava pensar que eram prostitutas, gays ou lésbicas. Ao trabalhar e ao consumir esses produtos, as vendedoras desconstruíram alguns de seus preconceitos, tiveram uma (re)definição dos limites morais e uma revisão ética, afirmando que, ao contrário do que elas imaginavam, as pessoas que mais procuram por esses produtos são mulheres que mantém uma relação afetiva institucionalizada (como namoro, casamento) e se autoidentificam como heterossexuais.

Virgínia (32 anos) não teve experiência em loja e apresentava os produtos em seu quarto ou na sala de sua residência e os levava para vender nas casas de amigas. Joana (24 anos) trabalhou por um ano em loja de sex shop que entregava kits para revendedoras e depois passou a trabalhar com catálogos pela mesma empre-

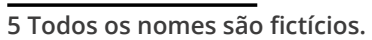

60 Sistema de Vendas Diretas (SVD) é o termo que legalmente nomeia a comercialização dos produtos feita por revendedores. A relação da empresa com os vendedores no SVD baseia-se na ausência de vínculos empregatícios: são juridicamente reconhecidos como "vendedores ambulantes". (ABíLIO, 2014, p. 13). 
Consumo de objetos eróticos por mulheres: processos e contextos... Anelise Montañes Alcântara • Marlene Tamanini

sa. Ela apresentava seus produtos na faculdade em que estudava e fazia reuniões coletivas (os chamados Clubes da Luluzinha) para apresentação dos objetos. Sara estava trabalhando em uma sex shop localizada no interior de uma loja de lingerie e pijamas. Tratava-se de um espaço pequeno, com variados cosméticos eróticos, poucos vibradores, dildos ou estimuladores sexuais.

A sex shop é um local de sociabilidade em que as vendedoras interagem com outras mulheres reiterando normas e rompendo-as. Os cotidianos das vendedoras são ricos em partilhar experiências, escutar confidências e falar de sexo faz parte de suas vidas. Elas parecem fazer justiça à posição de Brah (2006, p. 341) quando afirma que "nosso gênero é constituído e representado de maneira diferente segundo nossa localização dentro de relações globais de poder". Podemos agregar também as relações locais às situacionais.

As vendedoras participam dos sentidos de decolonialidade dos corpos, de si, da sexualidade e de gênero na medida em que se esmeram para apresentar os objetos e explicar como eles podem intermediar e melhorar as relações sexuais e afetivas de suas clientes. Elas constroem novas narrativas a respeito da sexualidade feminina e da feminilidade, produzindo novas invenções do feminino; assumem que se tratam de aspectos a serem explorados e de como os objetos podem ser usados para dar a felicidade que anunciam por meio de sua cor, sua forma, seu cheiro e das palavras a eles agregadas quando postos nas relações com o corpo e com a sexualidade.

Quanto ao consumo, ele se insere também em um conjunto de enunciados que subjetivam necessidades e que vendem ideias sobre uma sexualidade prazerosa, bem como permitem que as consumidoras e vendedoras desenvolvam uma quantidade de 
Consumo de objetos eróticos por mulheres: processos e contextos... Anelise Montañes Alcântara • Marlene Tamanini

técnicas e conhecimentos de si e de competências a respeito de como dar e obter prazer. Igualmente, os enunciados desenvolvem linguagens sobre práticas para manter relacionamentos que são ativos sexualmente e envolvem articulações novas a respeito da busca por orgasmos e por experiências de si. Então, os argumentos dos mercados que privilegiam uma forma de conhecimento baseada no desenvolvimento das tecnologias dos objetos têm que se confrontar com o que fazem as consumidoras, com o que pensam, o que compram e o que dizem. Desta forma, pressionam e impulsionam mudanças - que podem alargar as normas da sexualidade - e não apenas (re)produzir obediências.

Evidentemente, neste fazer, reitera-se uma produção discursiva que é gendrificada e se produzem novas questões de gênero ${ }^{7}$. Mas não parece ser pura e simplesmente o que é denominado por Bento (2010) de heteroterrorismo, no seu estudo para outro contexto ${ }^{8}$. Os discursos e os sentidos semióticos das vendedoras e dos mercados eróticos reatualizam a versão de uma mulher decidida, moderna, romântica, independente financeiramente e que cuida de si.

Esses objetos como tecnologias, no sentido foucaultiano (1990), possibilitam às consumidoras desta pesquisa efetuarem, por conta própria ou com a ajuda de outros, certo número de operações sobre seu corpo, sua alma, seu pensamento e sua conduta, obtendo assim uma transformação delas mesmas, com o desejo de alcançar certo estágio de felicidade. Trata-se também de um campo de desejos que se aproxima do que é descrito por Giddens (1993) como relacionamento puro. Ou seja, um vínculo emocional próximo e continuado com outra pessoa para extrair satisfação su-

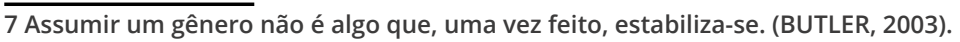

8 "As reiterações que produzem os gêneros e a heterossexualidade são marcadas por um heteroterrorismo contínuo". Tecnologias discursivas que preparam o corpo para que desempenhe com êxito o gênero. (BENTO, 2010, p. 4). 
Consumo de objetos eróticos por mulheres: processos e contextos... Anelise Montañes Alcântara • Marlene Tamanini

ficiente para cada um. Essa ideia de desejos pressupõe um campo partilhado de significação no qual o agir se inscreve. É desejo feito para si e para compartilhar com o outro, está inscrito no corpo e no sexo e faz parte de um campo que não é só de uma pessoa, pode ser só meu e pode estar inscrito também no experimentar com o outro, ou no exercício de uso de outra pessoa. (SAFATLE, 2014).

Esses processos se inserem, igualmente, na sexopolítica, expressão de Preciado (2008), que abrange o mercado farmacopornográfico. Porém, vai além desse lugar ao se conectar com a reflexividade das pessoas (no caso das mulheres). Assim, as mulheres compram, elegem e se engajam com a fantasia, fazem-se pessoas sob a expectativa do prazer (sexual e emocional) a ser obtido em sua vida sexual e afetiva, com relacionamentos fixos ou não. As mulheres com suas agências colocam para circular as estratégias e os enunciados de um novo jogo, parafraseando Foucault, no qual parece ser essencial tirar deste pequeno fragmento de si mesmas, não somente prazer, mas saberes e todo um jogo sutil que passa de um a outro: saber do prazer, prazer do saber. (FOUCAULT, 1993, p. 101).

Esses conhecimentos e práticas circulam pelos mercados eróticos como uma brincadeira entre adultos. Não é raro escutar o termo "brinquedo" ao se referirem aos vibradores, dildos, estimuladores da vulva e clitóris, o que, em certa medida, suaviza os seus conteúdos juntamente a sua materialidade rosa, lilás, e seu formato com bichinhos (como coelhinho, golfinho, borboleta). Esse brincar é parte de um dispositivo contemporâneo no mercado dos produtos eróticos e leva em conta outra razão de ser: "a mulher capaz de prender marido", como parte de uma agência que ela sabe fazer, e que se produz com a utilização do prazer sexual - situação 
Consumo de objetos eróticos por mulheres: processos e contextos... Anelise Montañes Alcântara • Marlene Tamanini

muito diferente do uso das artimanhas para obter gravidez e que, em certas situações, foram acionadas por diferentes mulheres.

Inventam-se novas formas de relacionalidade que, por vezes, seguem reiterando as convenções normativas sobre como evitar traições. Em outros casos, essas convenções são rompidas, pelo menos como possibilidades do desejo. Esse é um novo jeito de operar com seus planos, fantasias e expectativas. É uma posição subjetiva de mulheres engajadas com a ideia do prazer e com as condições para obtê-lo. São aspectos muito diferentes da sexualidade presente no amor romântico ou do imperativo do dever da procriação, que, embora possam ainda ser encontrados na contemporaneidade e em muitos contextos, neste caso, estão fora da expectativa sobre como as mulheres operam no uso, na compra e na venda das tecnologias eróticas. Esses conjuntos de aspectos são novos saberes e novas práticas, cujo sentido do consumo tem mais a ver com assegurar as relações apimentadas (quando são casadas) ou extrair delas o maior prazer possível, fazendo as consumidoras se sentirem desejadas no seu corpo, sexo, sexualidade. É parte de sua agência, com tomadas de decisões e engajamentos de si.

O discurso e o agenciamento das subjetividades são produtivos porque constituem imaginários e práticas que passam a interagir na vida das pessoas para a expressão de seus desejos de maneira lícita. Formata-se uma nova subjetividade e nova moralidade do uso sem culpa, sem o dever de prestar contas a alguém ou de informar a respeito de si. Se de um lado essa dinâmica é reiterativa das normatividades da sexualidade e de gênero, de outro ela constrói o engajamento da vontade e do desejo das usuárias.

É nesta direção que atuam as estratégias de venda. Decolonização de uma moralidade fechada à diversidade do viver, sem possibi- 
Consumo de objetos eróticos por mulheres: processos e contextos... Anelise Montañes Alcântara • Marlene Tamanini

lidades de falar, experimentar, ou melhor, decolonização do privado e de sua moralidade violenta pela grande proliferação de lançamentos ${ }^{9}$ e toda a gama de novidades em um mercado que é globalizado, a respeito de um tema que era quase somente experimentado como tabu. Isso significa dizer que não apenas os produtos são produzidos para serem vendidos pelas e para as muIheres no casamento, mas que nessas estratégias e enunciados se constrói a imagem da mulher decidida, moderna, independente e bem financeiramente, valores que não se encontravam em sociedades tradicionais. Na prática da vida, as mulheres nem se sentem e nem têm esse tipo de subjetividade sempre, ou lhes faltam as condições, mas a mensagem é: compre, use e você será assim.

Nesse processo, as mulheres consumidoras e vendedoras também instituem etiquetas, códigos de condutas, ditam comportamentos e fazem de si a própria propaganda daqueles objetos eróticos. Elas decolonizam as resistências em falar desses objetos e da sexualidade em diferentes lugares. Os processos de decolonização acontecem em muitos níveis, ainda que sejam mantidos enunciados heteronormativos e de espaços de um imaginário povoado pela valorização de relacionamentos institucionalizados duradouros e monogâmicos como hegemônicos nestas práticas. Existem muitos conteúdos contraditórios que fazem parte dessas narrativas de sexualidade, mas o fato é que as vendedoras valorizam seu trabalho como algo vinculado a melhorar a vida das muIheres, de pessoas com baixa autoestima, para salvar casamentos e para potencializar a felicidade conjugal e como práticas de si no uso para si. Existe, a partir delas, uma espécie de orientações e aconselhamentos, nos quais se ensina a viver a tecnologia da sexualidade, do sexo e de gênero de forma interativa.

$\overline{9 \text { Existem mais de } 40}$ sabores de géis para a prática do sexo oral no Brasil. (BISMARCHI, 2012). 
Consumo de objetos eróticos por mulheres: processos e contextos... Anelise Montañes Alcântara • Marlene Tamanini

Ressalta-se, contudo, que nem tudo está decolonizado. Muitos dos discursos que circulavam pelos mercados eróticos pesquisados eram machistas e conservadores, na medida em que atribuíam às mulheres heterossexuais a responsabilidade por manterem seus relacionamentos afetivos e sexuais. As vendedoras, frequentemente, operavam com enunciados sobre objetos que incitam as mulheres a agradarem seus companheiros, naturalizavam e essencializavam seus comportamentos como aquelas que estavam dispostas a se doarem mais na relação. Nesses enunciados, "[...] são elas que 'se expõem', no mesmo ato de se entregar à tarefa de satisfazer as necessidades afetivas do (s) outro (s) e num contexto de falta de reciprocidade". (ADELMAN, 2002, p. 59).

Os aspectos mais conservadores nas narrativas das vendedoras se expressam quando, ao considerarem o estado civil das mulheres que consomem a tecnologia erótica, aquelas enfatizam que há "necessidade" de sair da rotina, de apimentar a relação sexual, sem considerar a agência feminina, e atribuem, unicamente, um agir preocupado em satisfazer os desejos masculinos para que seu parceiro fique na relação e ela possa mantê-la. Em outras palavras, a mulher deve assumir o uso dos produtos para "manter o seu homem", evitando que ele "busque alguém fora da relação". Nesse caso, são discursos dos mercados eróticos direcionados às responsabilidades das mulheres heterossexuais, sobretudo das casadas. Eles gendrificam desigualmente as relações e normatizam comportamentos sexuais e amorosos femininos.

Para a vendedora Joana (24 anos), o estado civil faz diferença na hora da compra e da escolha do objeto. Segundo ela, as muIheres solteiras têm receio de comprar esses produtos, temendo preconceitos ou sanções por parte de seus parceiros sexuais. A vendedora assevera que, quando as mulheres estão envolvidas 
Consumo de objetos eróticos por mulheres: processos e contextos... Anelise Montañes Alcântara • Marlene Tamanini

em uma relação institucionalizada duradoura, como um namoro ou casamento, se estabelecem sentimentos de segurança e confiança para o uso desses objetos. No conjunto das práticas das vendedoras, as palavras e expressões frequentemente evocadas são "apimentar", "esquentar", "sair da rotina", "diversificar" e "acender a chama" do casal. Contudo, nem sempre essas expressões ou metáforas estão postas fora da agência das mulheres.

Assumimos o conceito de consumo artesanal, no qual acreditamos "que anunciantes e varejistas não são as únicas forças que influenciam a maneira como os consumidores escolhem fazer uso de bens" (CAMPBELL, 2004, p. 55). Aqui, um exemplo útil demonstra a criatividade de mulheres ao se apropriarem de objetos eróticos, como o gel denominado Tabu. Esse gel é um dessensibilizante para a prática de sexo anal. Em nossa pesquisa, observamos que tem sido utilizado para a prática de retirar as sobrancelhas. Prática voltada ao cuidado de si, ao embelezamento do corpo e da sexualidade.

As mulheres participantes da pesquisa utilizam os objetos eróticos para comunicar algo a seus parceiros. É possível que as mulheres se apropriem desses produtos para realçar, em vez de diminuir, seu sentimento por eles. Elas incitam seus parceiros para a prática do sexo por meio do uso dos objetos eróticos, sendo ativas no processo de se sentirem desejadas.

O antropólogo Daniel Miller (2013) afirma que as mercadorias continuam sendo utilizadas para comunicar, não necessariamente com a intenção de status, de obter admiração ou se distinguir e competir. O autor destaca como o significado de um produto pode ser transformado pelo contexto e pela maneira de seu uso. Pensar em um pênis de borracha pendurado em uma sex shop não é a mesma coisa que pensar em um pênis de borracha dentro da 
Consumo de objetos eróticos por mulheres: processos e contextos... Anelise Montañes Alcântara • Marlene Tamanini

vagina. Isto é, ele muda de significado e de qualidades dependendo do contexto em que for usado.

Miller trata o consumo como uma atividade. E Colin Campbell afirma essa atividade como artesanal, na medida em que os indivíduos apresentam habilidade, conhecimento, discernimento, amor, paixão, à ação de consumir. As mulheres vendedoras usam suas habilidades, conhecimentos, discernimento, amor, paixão nas práticas envolvidas com a compra, manipulação, narrativa e apresentação de usos dos objetos eróticos. Ao mesmo tempo, valorizam a tecnologia erótica com o controle dos elementos que poderiam se referir ao pânico moral, à devassidão ou para assimilar a muIher como prostituta ou pornográfica. Por isso, há todo um esforço para produzir imagens e linguagens sobre o belo, o bom, o gosto e a possibilidade de sedução e de cuidados de si decorrentes do uso do produto. Nesse contexto, as vendedoras evitam falar "pinto postiço de borracha", adaptando a abordagem, para separá-la da pornografia, do "vulgar", do erótico e focar na "elegância".

Como bem sugere Leite Júnior (2006), o debate que dicotomiza os termos e prazeres são espaços de uma luta simbólica pela legitimidade das representações e das práticas sexuais. A pornografia estaria ligada, nas representações, às classes populares e seus gostos "vulgares". Larissa Pelúcio (2007) mostra o cunho político do sexo e dos múltiplos discursos e o que se pretende legítimo a respeito dele, o que se faz dele. Nesse sentido, há uma preocupação das vendedoras a respeito de como oferecer os produtos, sobre quais produtos oferecer, como explicar o uso e como falar a respeito deles de maneira a minimizar ou evitar constrangimentos. Nessa direção, as empresas de produtos eróticos com foco em vendas diretas já estão produzindo catálogos com produtos considerados "baunilha" (mais leves) e os considerados mais 
Consumo de objetos eróticos por mulheres: processos e contextos... Anelise Montañes Alcântara • Marlene Tamanini

hard (mais pesados). Esses catálogos facilitam a comunicação das vendedoras ou das consultoras com suas clientes, também foram pensados para atingir o público das mulheres evangélicas e para serem olhados pelo casal. Com o intuito de usar estratégias para quebrar tabus, as vendedoras estão sendo aconselhadas a apresentar primeiro o catálogo "baunilha" e só mostrar outros (hard) se estes forem solicitados.

Supõe-se que exista a necessidade da construção de outros processos de subjetivação para usar, vender e engajar-se com os objetos eróticos. Há uma preocupação em salientar as propriedades "terapêuticas"10 dos objetos, como o uso da prótese peniana ${ }^{11}$ na melhora da aparência, na autoestima e no humor. Esses aspectos terapêuticos podem ser considerados novos discursos para despatologização moral, como uma estratégia que legitima o seu uso e decoloniza. Seria uma espécie de vantagem usar esses objetos em comparação com as pessoas que não os usam, na medida em que agregam propriedades que aparecem, então, como uma das formas de expressão de "um poder que gere a vida". (FOUCAULT, 2011).

Esse poder pode transformar o corpo em algo a ser melhorado, construído, um corpo rascunho, nas palavras de Le Breton (2007). Nesse sentido, circula o discurso da potência dos objetos, em que o corpo ganha cheiro, sensação de frescor, pele macia, lubrificação genital, constringe o tecido da vagina e ainda tira o desconforto e a dor na relação anal, conferindo-lhe uma maior resistência. Também é frequente um campo de linguagens que "entre quatro paredes vale tudo", ainda se esse "vale tudo" seja parte de um contraditório inscrito nas heteronormatividades. Assim, como o é, quando em muitos sentidos permanecem nos discursos insti-

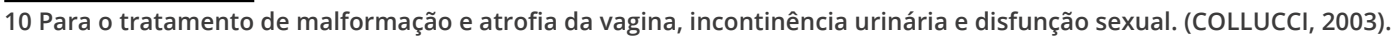
11 Foi o termo usado pela nativa, entretanto pode ser substituído pela palavra dildo.
} 
Consumo de objetos eróticos por mulheres: processos e contextos... Anelise Montañes Alcântara • Marlene Tamanini

tucionais dessas lojas, mercados, cursos de formação, alusões de que as mulheres estariam prontas e disponíveis para o ato sexual a qualquer momento. É um discurso que está na lógica do imperativo do gozo. O contraditório é que, por um lado, esse consumo se apresenta nas convenções estabelecidas pelos dispositivos de poder/biopoder e pela sexopolítica como reprodutor de gendrificações desiguais, já que cabem muitas responsabilidades às muIheres quanto a manter relacionamentos. Mas, por outro lado, são abertas possibilidades para a descoberta de si, do cuidado de si, do autoconhecimento como um campo imaginativo.

As descobertas de si e seus cuidados estariam voltados à constituição do corpo saudável, do sexo como passaporte para a saúde, do uso de produtos para o embelezamento do corpo, da higienização dele, preocupações com a aparência, com a vaidade, com a sensualidade e com a sedução. Nesses sentidos, essas relações se contradizem e também decolonializam o passado.

\section{Sentidos de decolonialidades: consumidoras de objetos eróticos}

Nesta pesquisa, foram entrevistadas como consumidoras de objetos eróticos: Olívia (25 anos), Adriana (27 anos), Penélope (29 anos), Tracy (31 anos), Lara (32 anos) e Lorena (33 anos). Todas as mulheres das seis entrevistas realizadas como consumidoras de objetos eróticos, em Curitiba, assumem vida sexual ativa e, em relação à entrada no universo amoroso/sexual, certificam um discurso que reitera um passado conectado a experiências com a repressão sexual, com um intenso controle familiar, de cunho moral e religioso e de relações convencionadas pela heteronormatividade. 
Consumo de objetos eróticos por mulheres: processos e contextos... Anelise Montañes Alcântara • Marlene Tamanini

Além disso, relatam como era frequente o medo exacerbado de uma gravidez indesejada. Todas iniciaram suas atividades sexuais em relacionamentos institucionalizados (cinco com namorado e uma com marido). Três eram casadas, uma estava em união estável e duas eram solteiras. Nenhuma delas possuía filhos. Somente uma era negra, as demais eram brancas. Em relação ao grau de escolaridade, duas possuíam ensino médio completo, uma era graduada e três pós-graduadas.

As narrativas delas colocavam os produtos como intermediadores de relações sexuais, mas também no âmbito do aumento da cumplicidade, do compartilhamento da intimidade e de possibilidades de diálogo no relacionamento afetivo ou no casamento, conferindo, segundo elas, uma maior qualidade ao relacionamento. Suas narrativas com o uso da tecnologia erótica falam de descobertas de si, de novas sensações, de mais intimidade, de surpreender o parceiro, apimentar e diversificar a relação sexual e de potencializar o prazer. Os usos que fazem e seus sentidos, frequentemente estão associados à curiosidade ou à comemoração de datas especiais no relacionamento.

No discurso das usuárias, podem-se encontrar, porém, outros elementos vinculados aos aspectos mais relacionais da sexualidade, como considerar que o uso daqueles objetos não está ligado apenas às relações sexuais, mas também diminuiria as fronteiras entre as pessoas e seus corpos, propiciando conversar mais abertamente sobre o sexo e aumentando o entrosamento do casal. Esse aspecto é observado na narrativa de Tracy (31 anos), segundo a qual, "na verdade não é para melhorar o sexo, mas para melhorar a relação com o outro. É algo que aproxima a pessoa da outra pessoa e que mostra [...] que você não está só preocupada com o seu prazer". 
Consumo de objetos eróticos por mulheres: processos e contextos...

Como encontrado nesse contexto, nos discursos dos mercados e das vendedoras, a questão do prazer feminino fica subsumida. Algumas usuárias falam abertamente sobre os seus prazeres, seus desejos e a respeito da potencialização de suas sexualidades ou do poder de sedução que desenvolvem com o uso dos objetos. No caso das mulheres solteiras, elas vivem relações amorosas mais descomprometidas e menos institucionalizadas, rompem as convenções de gênero que colocam as mulheres como passivas em relação aos seus desejos e prazeres sexuais. Não fazem sexo somente quando estão afetivamente ligadas a um parceiro, aspecto que destoa, em parte, dos discursos veiculados pelos mercados eróticos, mais focados na venda para o casal, embora a tese tenha demonstrado que esse aspecto está em franca mudança; é o que se pode observar na fala de Olívia (25 anos):

Em toda a relação, se o homem não goza, ele não termina. Eu também sou determinada; quem tem que gozar sou eu e não ele toda vez. Muitos deles não têm paciência e isso me irrita profundamente; daí eu tenho o vibrador. Você pode, por favor, pelo menos usar em mim?

Nessa fala temos parceiros diferentes e ela se conecta à crítica ao orgasmo dirigido sempre para o masculino. Evidencia-se uma decolonialidade da sexualidade e do gênero, uma vez que Olívia se posiciona como sujeito de direito a um sexo bom e justo, ou seja, ao seu orgasmo. Gera-se tensão sobre o modelo androcêntrico de sexualidade, na medida em que sexo é também quando a mulher goza, mas ainda se preserva aspectos do contraditório, quando ativa um simbólico para o uso do vibrador, cuja concepção segue inscrita no ideário heteronormativo. Também existem preocupações em não propor o uso desses objetos na primeira 
Consumo de objetos eróticos por mulheres: processos e contextos... Anelise Montañes Alcântara • Marlene Tamanini

relação sexual, isto poderia circunscrever a mulher na prostituição, na pornografia, ou no ilícito moral. É preciso que se construa intimidade suficiente para tal, do contrário poderia parecer vulgar, inadequado, o que resultaria em desestímulo.

Assim, Lorena (33 anos) diz: "Não dá para usar esses produtos com uma pessoa com quem você se relaciona apenas uma noite [...]; quando não tem amizade ou um tempo de relação não é legal". Outras mulheres esperam o homem falar sobre o uso de algum objeto, mesmo se elas já haviam utilizado em relações anteriores. Parece que, por vezes, as mulheres precisam preservar sua representação pueril para manterem-se valorizadas no campo da afetividade. Esses aspectos seguramente são de uma concepção colonizada por sexismos e desigualdades, imaginários nos quais a decolonização dos binários e das desigualdades não chegaram, mesmo quando elas consomem produtos eróticos.

De certa forma, ainda vivemos entre o paraíso e o inferno sexual, entre o permissivo e o tolerado, o repressivo e o violento, como bem coloca Sérgio Carrara (2005). Esses processos também são marcados por uma hierarquia no uso daqueles produtos, sobre quando usar, que objetos podem ser usados; não somente uma preocupação com quem usar (quando se tem intimidade) ou em um relacionamento institucionalizado.

Lorena (33 anos) e Tracy (31 anos) expõem as hierarquias do uso: começaram suas idas a sex shops à procura de preservativos diferentes, somente na época em que ambas estavam em uma relação duradoura. Lara (32 anos) somente adquiriu vibrador e borboleta vibratória com seu marido, apesar de já ter utilizado objetos sexuais com dois parceiros anteriores. Penélope (29 anos) ainda não adquiriu vibrador ou estimuladores, mas está pensando em adquirir no futuro, o que reafirma que os objetos eróticos primei- 
Consumo de objetos eróticos por mulheres: processos e contextos... Anelise Montañes Alcântara • Marlene Tamanini

ramente incorporados são os mais palatáveis, mais aceitos pelos padrões vigentes da sexualidade e de gênero. Isto é, os cosméticos são os objetos eróticos mais consumidos no Brasil. Um dos fatores desse consumo estaria no preço mais acessível quando comparado ao valor dos vibradores, dildos e estimuladores sexuais, e porque são mais aceitáveis, considerando-se a expectativa do/a parceiro/a. O gel (classificado como cosmético) é um facilitador da penetração, que pode também ser indicado por ginecologistas.

Observa-se que esses mercados apresentam investimentos diversificados e preocupados com que sejam palatáveis ao consumo. Percebe-se um esforço da indústria no desenvolvimento de vários vibradores escamoteados, pois, em boa medida, ainda refletem elementos da cultura que são interditados. Esses objetos são encontrados frequentemente nas cores que lembram os brinquedos infantis de meninas, como apontado anteriormente, conferindo-lhes neutralidade e uma ideia inofensiva (WHALTER, 2017). Eles também funcionam como tecnologias de produção de gêneros, isto é, nas interações cotidianas, somos instados a continuar reproduzindo a naturalização dos gêneros e da sexualidade (BENTO, 2010). Dado isso, interessa-nos se há matizes de deslocamentos dos usos e se as experiências estão rompendo sentidos ligados só ao contexto do casamento, ou só para heterossexuais e só para mulheres com mais de 30 anos, tendência que os estudos de Gregori (2012) haviam mostrado. No entanto, estudos mais recentes apontam mudanças que ampliam essa faixa etária incluindo mulheres mais jovens e mulheres com até 70 anos. (WHALTER, 2017).

Embora os objetos sejam confeccionados numa tentativa de diminuir a vergonha associada a seu uso, os discursos dos mercados legitimem sua inserção em relacionamentos estáveis e dura- 
Consumo de objetos eróticos por mulheres: processos e contextos... Anelise Montañes Alcântara • Marlene Tamanini

douros e as lojas de sex shops tenham se transformado em locais convidativos para o público feminino, não é de todo factual que as mulheres se sintam livres para usá-los. Lara (32 anos) se sente inibida para falar sobre seus prazeres corporais livremente. Em nenhum momento da entrevista ela fala sobre seu prazer, orgasmo ou masturbação.

Esses conteúdos propiciam reflexões acerca do sistema sexo/ gênero e da sexopolítica de Preciado (2002), demonstrando ainda marcas da dupla moral, na qual a mulher continua sendo objeto de normas regulatórias, de relações de poder e de aprisionamento do seu corpo, desejo e prazer. Por outro lado, os discursos das ciências da saúde são apropriados pelos mercados de objetos eróticos e pelos meios de comunicação de massa, quando põem foco no prazer e no orgasmo feminino. Isto produz espaços para as narrativas decolonizadoras das práticas e mesmo para positivá-las, também reforçadas pelas vendedoras.

As usuárias discordam em relação a usar ou não vibradores e dildos durante suas relações sexuais, apresentando contradições nas suas falas, o que denota que estamos falando de "mulheres" e não mulher como categoria única e universal. Elas são mulheres com diferentes exercícios de sua sexualidade, dos seus prazeres e desejos corporais. Logo, nem todas buscam esses mercados para relacionamentos a dois. Não é incomum que usem vibradores para o próprio prazer e liberdade fora das relações sexuais do casal, o que também identificamos na tese.

Os mercados, principalmente o de face a face das vendedoras das sex shops e das consumidoras com as consultoras, têm sido percebidos como locais de empoderamento das mulheres com ideias sobre a sexualidade, o prazer, o sexo e o gênero. Entretanto, abordar o empoderamento feminino conectado à sexualidade é 
Consumo de objetos eróticos por mulheres: processos e contextos... Anelise Montañes Alcântara • Marlene Tamanini

um terreno um tanto perigoso, na medida em que o sexo deve ser percebido como uma prática possível de ser exercida pelas mulheres conforme suas vontades e desejos, mas não para atender a prescrições ou a novas normatizações a serem seguidas para performances de mulheres modernas e ativas sexualmente. Joice Berth (2019), feminista do movimento negro, em seu livro “Empoderamento", aborda como o conceito do empoderamento tem sido propagado de forma enviesada, na medida em que ele não pode ser compreendido desconectado do contexto coletivo, não pode ser apenas do âmbito individual. Como ficar empoderada em um país com tantos casos de feminicídios como no Brasil?

Percebemos uma mudança na sexualidade feminina no exercício de suas práticas sexuais com o uso de objetos eróticos, que ora performatizam-se mais próximo das normas e ora menos próximo delas. Nessas performances, há espaço para resistências e para novas invenções do feminino. Nesse sentido, gênero não significa sempre a mesma coisa (STRATHERN, 2006), com as mesmas relações que determinam uma dominação masculina. Essa é uma percepção ligada à decolonialidade. A performatividade é “um tipo de ação que pode potencialmente proliferar-se além dos limites binários impostos pelo aspecto binário aparente do sexo". (BUTLER, 2003, p. 163-164). O fazer gênero como performatividade implica evidenciar uma multiplicidade de gênero que extrapola o mundo ocidental moderno. Ou seja, "isso não quer dizer que esse fazer seja sempre binário, ou que sendo binário seja sempre de dominação ou que seja sempre tomado como organização linear entre sexo-gênero-desejo". (GOMES, 2018, p. 72).

Tracy (31 anos), por exemplo, acredita que os vibradores e dildos tragam independência e autonomia para as mulheres. Para ela e a Lorena (33 anos), os vibradores devem ser usados individu- 
Consumo de objetos eróticos por mulheres: processos e contextos... Anelise Montañes Alcântara • Marlene Tamanini

almente. Lorena prefere mais "o sexo a dois" (isto é, somente ela e o parceiro sexual) e não vê graça no uso individual do vibrador. Adriana (27 anos) considera desestimulante o uso dos vibradores e dildos na relação sexual, pois prefere ser estimulada pelo parceiro. Ela diz: "[...]. Não curto muito, mesmo de fantasias, essas coisas; eu gosto de ser quem sou. [...], não gosto de coisas que focam muito a região pélvica do homem, porque acho que foca muito na coisa; empobrece". Olívia (25 anos) carrega seu vibrador na bolsa e pede para seus parceiros usarem nela, sem nenhum problema. Lara só usa os objetos acompanhados do seu marido, mesmo achando "excelente" o uso da borboleta vibratória.

Os discursos que circulam nos mercados eróticos sustentam a imagem de mulher decidida, moderna e independente, produzindo novas invenções do feminino para mulheres que se utilizam dessas tecnologias. Essa linguagem é incorporada por Olívia (25 anos), Lara (32 anos) e Penélope (29 anos), conferindo-lhes, segundo elas, uma potencialização das suas sexualidades e de seus poderes de sedução no seu jeito de sentir e viver. Elas se sentem desinibidas com o uso. Para as consumidoras, o uso dessas tecnologias Ihes confere um aumento da excitação, dá uma qualidade lúdica para o sexo, a relação sexual não fica "naquele mais ou menos". Os produtos passam a ser um motivo, um instrumento que incita à prática do sexo.

Portanto, investe-se nos objetos eróticos para alcançar "algo" a mais para o sexo e a sexualidade, algo que faça o corpo funcionar melhor. Algumas também investem no cenário, no contexto, com uma preparação que requer tempo. Esses elementos mostram que elas extraem prazer da imaginação e do humor proporcionado pelo jogo lúdico do uso e do consumo dessas tecnologias, auxiliando a criação de formas diferentes de fazer sexo. Mesmo 
Consumo de objetos eróticos por mulheres: processos e contextos...

Anelise Montañes Alcântara • Marlene Tamanini

que exista a tentativa de agradar o outro, elas estão extraindo prazeres dessas dinâmicas sexuais.

[...] Eu acho que as pessoas usam [produtos] porque elas acreditam que dá pra ter uma vida sexual muito boa e continuar a descobrir coisas diferentes na mesma pessoa, pra não ter que procurar outra pessoa diferente, pra ter sensações diferentes com essa mesma pessoa que você está. É querer manter um relacionamento saudável, que tenha paixão, que seja além do fraternal, pra não chegar no limite de ser só amigos. (Penélope, 29 anos).

Aspectos da decolonização são apontados quando as agências dessas mulheres são de sujeitas ativas que interagem com o uso, a compra, a oferta e a imaginação sobre o que pode ser extraído daqueles objetos. Esses aspectos aparecem ao se considerarem as emoções que impulsionam, as que se podem extrair do uso, aquelas que são simultaneamente tornadas possíveis e as que são limitadas pelos recursos conceituais e linguísticos no que tange à sexualidade e aos contextos da vida social, cultural das consumidoras. É aqui que entra o conteúdo do vivido, a noção de experiência como campo a experimentar. Nada está dado, embora no conteúdo empírico possam ser reconhecidos grandes rasgos de mercantilização do desejo e até de discursos coercitivos, há que se reconhecer também grandes processos de mudanças nos conceitos, nos usos, nas práticas.

Essas mulheres são sujeitas de topografias multidimensionais. Logo, suas narrativas diversas e múltiplas têm igual valor para o campo das subjetividades e para os modos de se viver. Ainda que o uso dos objetos eróticos se insira na lógica do sexo produtivo e ressignificado nos mercados, ele é apropriado a partir de múltiplas 
Consumo de objetos eróticos por mulheres: processos e contextos... Anelise Montañes Alcântara • Marlene Tamanini

construções pelas mulheres, na medida em que as performances, desejos, as emoções e os sentidos são conectados em múltiplas articulações imaginárias e em processos de subjetivação que não podem ser reduzidos simplesmente a um corpo dócil. No mais, esses novos processos já foram introduzidos em diferentes contextos sociais e em práticas híbridas.

As mulheres se instituem nos mercados eróticos como sujeitas desejantes, o fazem por si e pelo outro. É uma maneira relacional de atuar nas formas de apropriações dos seus corpos, orgasmos e prazeres sexuais. As transformações das sexualidades contemporâneas estão se produzindo por coletivos heterogêneos nos quais participam as mulheres e uma série de agências que interagem relacionalmente. Essas interações estão produzindo na prática corpos que gozam, estão performatizando e materializando esses corpos e possibilitando viver experiências mais livres.

\section{Conclusão}

Ao analisarmos a apropriação dos objetos eróticos na vida sexual das participantes da pesquisa, compreendemos como suas experiências e narrativas, por diversas vezes, nos remetem às noções normativas do que deveria ser um "sexo ideal", mesmo quando se usa cinta-liga, fantasias, vibradores, géis e lingeries. Contudo, estão ocorrendo processos de decolonização destas lógicas de submissão do feminino ao desejo masculino. Esse processo de desidentificação do binário em direção ao prazer de si é crucial para a autonomia e parece estar mais expandido nos desejos, imaginações, fantasias e práticas sexuais das mulheres consumidoras. 
Consumo de objetos eróticos por mulheres: processos e contextos... Anelise Montañes Alcântara • Marlene Tamanini

Nessa perspectiva, acreditamos que as narrativas das mulheres indicam o que elas podem ser e o que já são: protagonistas dos seus erotismos. Indicam ainda que elas possam escapar de algumas convenções de gênero ao incorporarem produtos eróticos em lógicas que não sejam reduzidas a agradar só ao "outro" (nas hierarquias da dominação), mas que também estabeleçam novas possibilidades para a expressão de sua sexualidade, da liberdade e da criatividade. Apesar de termos visualizado nesta pesquisa a incitação e a coerção para o uso das tecnologias eróticas por muIheres heterossexuais, observamos também sua possibilidade reflexiva e suas escolhas.

As práticas que envolvem o uso das tecnologias eróticas e as relações de poder formam domínios de saber, produzindo novas formas de ser sujeito no exercício de suas agências. As relações tradicionais de gênero ainda não desapareceram por completo, apesar da colonialidade do desejo, que muitas vezes aparece como: "quero ser desejada e faço de tudo para que ele me veja", as consumidoras também sabem provocar seus parceiros para que eles entrem nas dinâmicas dos desejos delas, o que aponta uma mudança significativa nessas relações e no sentido de sua capacidade de agenciar.

O fato é que contemporaneamente as mulheres que interagem com objetos eróticos se fazem notadas, são ativas nesses mercados e os usos também se voltam para si. Portanto, se de um lado, são partícipes do mesmo desejo de prazer que é proposto pelos produtos, elas também desejam ser performáticas e isso é parte da sua fonte de prazer. Os mercados eróticos, as sex shops e os modos como esses produtos são apropriados pelas participantes desta pesquisa, bem como por um conjunto de outras, inseridas no contexto, vem mostrando formas de subjetivação e de 
Consumo de objetos eróticos por mulheres: processos e contextos... Anelise Montañes Alcântara • Marlene Tamanini

cuidados de si, que são diluidoras das fronteiras entre o público e o privado, entre o corpo e a agência, entre o sexo solitário e/ou a relação unicamente para o prazer do outro.

O consumo e uso dos produtos eróticos as tornam técnicas úteis e eficazes à articulação de imaginários e de práticas sexuais consigo mesmas e com outras pessoas. Identifica-se engajamento com um dispositivo do fazer sexo para finalidades como melhorar uma relação no casamento, construir novos imaginários sobre o potencial sexual a ser explorado e de como essas práticas podem ser usadas para dar a felicidade que anunciam por meio de sua cor, sua forma, seu cheiro e das palavras a eles agregadas e às expectativas orgásticas.

Disso, tem-se um processo que se institui à medida da institucionalização de possibilidades, desejos e novos consumos. Para isso, os argumentos envolvem a venda, a compra, a manipulação, a fruição, a apropriação e o uso dos produtos, bem como envolvem enunciados sobre os benefícios, as estratégias das marcas, os modelos, as formas, as cores, a materialidade, os tamanhos, os locais onde podem ser encontrados, os custos e o gozo que prometem, o que com eles se institui como parte da experiência contemporânea de mulheres com seus companheiros e consigo mesmas.

Assim, trata-se de um lado, da venda de produtos com seus saberes já incorporados como eróticos e, de outro, da utilização do mundo material como uma experiência prática de mulheres envolvendo sexo, imaginação, dinheiro, jogos lúdicos, expressão da individualidade e da criatividade, prazeres sexuais e emocionais. Esses aspectos que implicam trocas intersubjetivas, que incluem motivações, estratégias de aproximação ou afastamento, critérios 
Consumo de objetos eróticos por mulheres: processos e contextos... Anelise Montañes Alcântara • Marlene Tamanini

de escolha, expectativas, prazer, desprazer, representações acerca do que se experimenta e ressignificações do vivido.

Esse sexo não é repressivo, é constitutivo da afirmação da sexualidade feminina, por meio de outros discursos e de outros enunciados de poder e de verdade, que se de um lado chegam "às mais tênues e mais individuais das condutas" (FOUCAULT, 1985, p. 13), de outro, propiciam experiências e cuidados de si fora da ordem repressiva.

\section{Referências}

ABÍlio, Ludmila Costhek. Sem maquiagem: o trabalho de um milhão de ReVendedoras de cosméticos. São Paulo: Boitempo Editorial, 2014.

ADELMAN, Mirian. GÊNero na CONStrução de SUbjetividAde. In: adelman, Mirian; Silvestrin, Celsi Brönstrup. Gênero Plural. CURITIBA: UFPR, 2002. P. 49 - 61.

AlCÂNTARA, Anelise Montañes. Orgasmos performados: materialidades e SOCIABILIDADES CONSTITUÍDAS POR UMA REDE DE ELEMENTOS HETEROGÊNEOS. 2017. 250f. Tese (Doutorado em Sociologia) - Universidade Federal do Paraná, CURITIBA, 2017.

AlCÂNTARA, Anelise Montañes. Chupa que é de uva: subjetividades INSTITUÍDAS COM O USO DE PRODUTOS ERÓTICOS. 2013. 148F. DISSERTAÇÃO (Mestrado em Sociologia) - Universidade Federal do Paraná, Curitiba, 2013.

Bento, Berenice. As tecnologias que fazem os Gêneros. Vill Congresso Iberoamericano de Ciência, Tecnologia e Gênero. 5 a 9 de abril de 2010. 
Consumo de objetos eróticos por mulheres: processos e contextos... Anelise Montañes Alcântara • Marlene Tamanini

DISPONIVEL EM: HTTP://FILES.DIRPPG.CT.UTFPR.EDU.BR/PPGTE/EVENTOS/CICTG/CONTEUDO_CD/E8_As_TECNOLOGIAS_QUE_FAZEM_os_G\%C3\%AANEROS.PDF. ACESSO EM: 20 JUL. 2014.

Berth, Joice. Empoderamento. São Paulo: Suel Carneiro; Pólen, 2019.

BISMARCHI, Ângela. De 4 com Ângela Bismarchi. Disponível

EM: HTTP://VIRGULA.UOL.COM.BR/VER/VIDEO/DE-4-COM-ANGELA-BIS-

MARCHI/2011/12/05/11627-PAULA-AGUIAR-PRESIDENTE-DA-ABEME-NOMEIA-ANgela-como-embaixatriz. Acesso em: 14 out. 2012.

BraH, Avtar. Diferença, Diversidade, Diferenciação. Cadernos Pagu, n. 26, P. 329-376, JAN./JUN. 2006.

BRAGAGlia, Ana Paula. Comportamentos de consumo na Contemporaneldade. Comunicação, mídia e consumo, São Paulo, v. 7, N. 19, P. 107-124, JUL. 2010.

BUtLer, Judith. Problemas de gênero: feminismo e subversão da IDentiDAde. Rio de Janeiro: Civilização brasileira, 2003.

CAMPBELL, Colin. Eu COMPRo, logo SeI Que EXISTO: AS BASES METAFísICAS do consumo moderno. In: BARBOSA, Lívia, CAMPBELL, Colin (Orgs.).

Cultura, consumo e identidade. Rio de Janeiro, FGV, 2006.

CAMPBELL, Colin. O consumidor ARTESÃo: CULTURA, ARTESANIA E CONSUMO em uma sociedade pós-moderna. Antropolítica, Niteróı, N.17, P. 45-67, 2004.

CARRARA, Sérgio. O Centro Latino-Americano em SeXualidade e direitos humanos e o “lugar” da homossexualidade. In: GROSSI, Miriam Pillar et al. (Orgs.). Movimentos Sociais, educação e SeXualidades. Rio de Janeiro: GARAMOND, 2005. P. 17-24. 
Consumo de objetos eróticos por mulheres: processos e contextos...

Anelise Montañes Alcântara • Marlene Tamanini

COllinS, Patricia Hill. Black Feminist Thought: Knowledge,

Consciousness, and the Politics of Empowerment. Segunda edição. NeW

YORK: ROUTLEDGE, 2000.

COllucCl, Cláudia. Produtos eróticos ganham aval de médicos. Folha

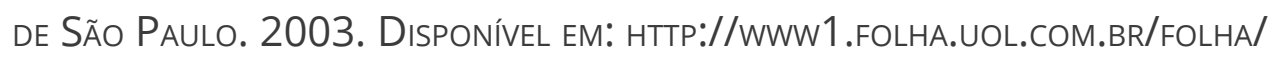
EQUILIBRIO/NOTICIAS/ULT263U2755.SHTML. ACESSO EM: 15 JAN. 2012.

FElSKI, Rita. Literature after Feminism. Chicago e Londres, The University of Chicago Press, 2003.

Foucault, Michel. As palavras e as coisas. São Paulo: Martins Fontes, 1995.

foucAult, Michel. História da Sexualidade I: A vontade de saber. RJ: GraAL, 2011.

FOUCAUlt, Michel. Scientia SeXualis; O Dispositivo da SeXualidade. IN: História da sexualidade: vontade de SABer. Rio de Janeiro, Graal, v. 1. 1993. P. 51-123.

FOUCAUlt, Michel. Tecnologias del yo y otros textos afines. Paidós, 1990.

FOUCAUlt, Michel. História da sexualidade: O cuidado de Si. Rio de JANEIRO, GRAAL, 1985. (v. 3).

GIDDENS, ANTHONy. A transformação dA Intimidade: SEXUALIDADE, AMOR E erotismo nas sociedades modernas. São Paulo: Editora UNESP, 1993.

FOUCAUlt, Michel. As consequências da modernidade. 2 ed. São Paulo: UNESP, 1991.

GOMes, Camilla de Magalhães. Gênero como categoria de análise decolonial. Civitas, Porto Alegre, v. 18, n. 1, P. 65-82, jan./abr. 2018. 
Consumo de objetos eróticos por mulheres: processos e contextos... Anelise Montañes Alcântara • Marlene Tamanini

GreGori, Maria Filomena. Erotismo, mercado e gênero: uma etnografia dos sex shops de São Paulo. Cadernos Pagu, Campinas, v. 38, p. 53-97, 2012.

Gregori, Maria Filomena. Prazer e perigo: notas sobre feminismo, seXSHOPS E S/M. Ide, SÃo PAulo, v. 1, P. 81-91, 2005.

HALL, Stuart. Quando fol o pós-colonial? Pensando no limite. In: HALL, Stuart. Da diáspora: IDENTIDAdes E mediações Culturais. Belo Horizonte: EditORA UFMG, 2003. p. 101-131.

HARAWAY, DonNA. Simians, cyborgs, AND WOMEN: THE REINVENTION OF NAture. New York: Routledge, 1991.

hOOKS, bell. Intelectuais negras. Estudos Feministas, Florianópolis, v. 3, N. 2, P. 464-469, 1995.

Le BReton, David. Adeus ao corpo: antropologia e sociedade. São PAULO: PAPIRUS, 2007.

LEITE JÚNIOR, JoRge. Das MARAVILHAS E PROdígios SEXUAIS: A PORNOGRAFIA bizarra como entretenimento. São Paulo, Annablume, 2006.

LUGONeS, María. Rumo a um feminismo descolonial. Revista Estudos Feministas, Florianópolis, v. 22, N. 3, P. 935-952, 2014.

MILLER, Daniel. Trecos, troços e coisas: estudos antropolóGicos SObre A CULTURA MATERIAL. RIO DE JANEIRO, ZAHAR, 2013.

Pelúcio, larissa. As maravilhas do sexo que ri de si mesmo. Cadernos Pagu, Campinas, v. 29, P. 481 - 488, JUl./dez. 2007.

PRECiado, Beatriz. Testo Yonqui. Madrid, Espasa Calpe, 2008. PRECIADO, Beatriz. Manifiesto contra-sexual: prácticas subVersivas de identidad seXual. Madrid, Opera Prima, 2002. 
Consumo de objetos eróticos por mulheres: processos e contextos... Anelise Montañes Alcântara • Marlene Tamanini

Rago, Margareth. Narcisismo, sujelção e estéticas da existênCia. Verve, V. 9, Р. 236-250, 2006.

REIS, LoRena Mochel. ERotismo gospel: MeRCAdos e Limites dA SEXUALIDAdE entre evangélicas (os) no complexo do Alemão. Religião e Sociedade, Rio de JANEIRO, v. 37, N. 1, P. 65-87, 2017.

SAFATLE, VLADIMIR. ERotismo, SEXUALIDADE E GÊNERO: CURSO MINISTRADO POR Vladimir Safatle. 2014.

STRATHERN, MARILYN. O GÊNero dA DÁDIVA: PROBlemAS COM AS MULHERES E problemas com a sociedade na Melanésia. Campinas, Unicamp, 2006.

Walther, Luciana Castello da Costa Leme. Mulheres que não ficam sem PILHA: COMO O CONSUMO ERÓTICO FEMININO ESTÁ TRANSFORMANDO VIDAS, RELAcionamentos e a sociedade. Rio de Janeiro, Mauad, Belo Horizonte, MG: FAPEMIG, 2017. 